\section{(2) \\ BRAZIULIAN JOURNAL \\ OF MEDICAL AND BIOLOGICAL RESEARCH}

www.bjournal.com.br
ISSN 0100-879X

Volume 45 (7) 565-680

July 2012

CLINICAL INVESTIGATION

Braz J Med Biol Res, July 2012, Volume 45(7) 617-624

doi: 10.1590/S0100-879X2012007500070

Prognostic significance of snail expression in hilar cholangiocarcinoma

Dalu Kong, Jun Liang, Rong Li, Shihai Liu, Jigang Wang, Kejun Zhang and Dong Chen

The Brazilian Journal of Medical and Biological Research is partially financed by

\section{욛NPq}

da Ciência e Tecnologia

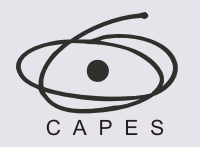

Ministério da Educação

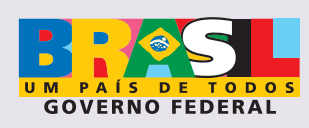

DTFAPESP

Institutional Sponsors

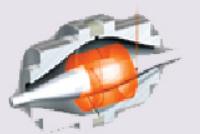

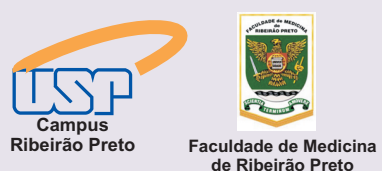

de Ribeirão Preto

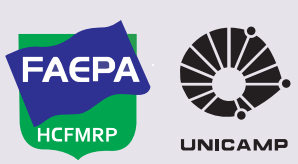

lore High - Performance MS Orbitrap Technology

Ф SHIMADZu

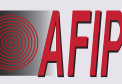

Associaç
Fundo de Incentivo
à Pesquisa

\section{analitica Thermo}




\title{
Prognostic significance of snail expression in hilar cholangiocarcinoma
}

\author{
Dalu Kong ${ }^{1}$, Jun Liang ${ }^{2}$, Rong $\mathrm{Li}^{1}$, Shihai Liu³, Jigang Wang ${ }^{2}$, \\ Kejun Zhang ${ }^{4}$ and Dong Chen ${ }^{4}$ \\ ${ }^{1}$ Department of Hepatobiliary Surgery, \\ Tianjin Medical University Cancer Institute and Hospital, Hexi District, Tianjin, China \\ 2Department of Oncology, Affiliated Hospital of Medical College, \\ Qingdao University, Qingdao, Shandong Province, China \\ ${ }^{3}$ Department of Laboratory Center, Affiliated Hospital of Medical College, \\ Qingdao University, Qingdao, Shandong Province, China \\ ${ }^{4}$ Department of General Surgery, Affiliated Hospital of Medical College, \\ Qingdao University, Qingdao, Shandong Province, China
}

\begin{abstract}
Many patients with hilar cholangiocarcinoma $(\mathrm{HC})$ have a poor prognosis. Snail, a transcription factor and E-cadherin repressor, is a novel prognostic factor in many cancers. The aim of this study was to evaluate the relationship between snail and $\mathrm{E}$-cadherin protein expression and the prognostic significance of snail expression in HC. We examined the protein expression of snail and E-cadherin in $\mathrm{HC}$ tissues from 47 patients (22 males and 25 females, mean age 61.2 years) using immunohistochemistry and RT-PCR. Proliferation rate was also evaluated in the same cases by the MIB1 index. High, low and negative snail protein expression was recorded in 18 (38\%), 17 (36\%), and 12 (26\%) cases, respectively, and 40.4\% (19/47) cases showed reduced E-cadherin protein expression in $\mathrm{HC}$ samples. No significant correlation was found between snail and Ecadherin protein expression levels $(P=0.056)$. No significant correlation was found between snail protein expression levels and gender, age, tumor grade, vascular or perineural invasion, nodal metastasis and invasion, or proliferative index. Cancer samples with positive snail protein expression were associated with poor survival compared with the negative expresser groups. Kaplan-Meier curves comparing different snail protein expression levels to survival showed highly significant separation $(\mathrm{P}<$ 0.0001 , log-rank test). With multivariate analysis, only snail protein expression among all parameters was found to influence survival $(P=0.0003)$. We suggest that snail expression levels can predict poor survival regardless of pathological features and tumor proliferation. Immunohistochemical detection of snail protein expression levels in routine sections may provide the first biological prognostic marker.
\end{abstract}

Key words: Hilar cholangiocarcinoma; Prognostic marker; Snail; E-cadherin; Immunohistochemistry

\section{Introduction}

Most patients with hilar cholangiocarcinoma $(\mathrm{HC})$ are difficult to treat and have an unfavorable prognosis. Complete surgical resection of $\mathrm{HC}$ is the only method to improve the cure rate of these patients. However, many patients with $\mathrm{HC}$ treated by curative resection have a poor outcome (13). Thus, the search for a prognosis factor is justified for the treatment of patients with $\mathrm{HC}$.

Epithelial-mesenchymal transition (EMT) is a complex stepwise phenomenon that occurs during embryonic development and tumor progression, and that also has a crucial role in chronic inflammatory and fibrogenic disease (4). EMT is characterized by the disruption of intercellular junctions, replacement of apical-basolateral polarity with front-to-back polarity and acquisition of migratory and invasive phenotypes. It is a critical early event for the invasion and metastasis of many carcinomas (5). The loss of E-cadherin is the hallmark of EMT. Several transcription factors have been implicated in the transcriptional repression of E-cadherin, including zinc-finger proteins of the snail/

Correspondence: Dong Chen and Kejun Zhang, Department of General Surgery, Affiliated Hospital of Medical College, QingDao University, No. 16, Jiangsu Road, QingDao, Shandong Province, 266003 China. Fax: +86-532-829-13054. E-mail: chendong.sdqd@ yahoo.com.cn and zjdx2008@126.com

Received June 9, 2011. Accepted April 13, 2012. Available online May 11, 2012. Published July 2, 2012. 
slug family, Twist, ZEB1, SIP1 and the basic helix-loop-helix factor E12/E47 (6,7). Snail was the first to be discovered (8) and is the most important transcriptional repressor of E-cadherin (9).

Snail was identified in Drosophila as a suppressor of the transcription of shotgun (an E-cadherin homologue) in the control of embryogenesis (10). Snail has a central role in morphogenesis since it is essential for the formation of the mesoderm and neural crest, which requires large-scale cell movements in organisms ranging from flies to mammals. The absence of snail is lethal because of severe defects at the gastrula stage during development (11). Snail has a fundamental role in EMT and breast cancer metastasis by suppressing E-cadherin expression. In fact, overexpression of snail was recently found in both epithelial and endothelial cells of invasive breast cancer but was undetectable in normal breast tissue $(12,13)$. The expression of snail in breast carcinomas is associated with metastasis, tumor recurrence and poor prognosis (14). Snail is also up-regulated in ovarian carcinomas (15), melanomas (16), oral squamous carcinomas (17), and hepatocellular carcinomas (18), being also associated with metastasis and a poor prognosis (14-18).

The expression of slug, a protein in the snail family, is a novel prognostic marker for human intrahepatic cholangiocarcinoma with lymph node metastasis (19). In the present study, we analyzed the expression of snail by immunohistochemistry in 47 resected human $\mathrm{HC}$ specimens and its relationship with E-cadherin. The expression of snail was analyzed with respect to the main pathological prognostic variables of $\mathrm{HC}$, proliferation index and overall survival.

\section{Material and Methods}

\section{Patients and tissue samples}

Formalin-fixed and paraffin-embedded samples from 47 patients ( 22 males and 25 females) with primary $\mathrm{HC}$ were obtained from the Hepatobiliary Surgery Center, Tianjin Medical University Cancer Institute and Hospital, from 2000 to 2005 . The mean age of the patients was 61.2 years. All tumors were diagnosed histologically, graded, and defined as moderately differentiated (grade $2 ; \mathrm{N}=29$ ) or poorly differentiated (grade 3; $N=18$ ). Tumors were also grouped according to the presence $(\mathrm{N}=15)$ or absence $(\mathrm{N}=32)$ of neoplastic vascular thrombosis and the presence $(\mathrm{N}=16)$ or absence $(\mathrm{N}=31)$ of neoplastic perineural invasion (Table 1). Follow-up ranged from 1 to 60 months from the date of surgery (mean, 13.1 months). The 47 patients did not receive postoperative adjuvant therapy, such as chemotherapy, radiotherapy or any other treatment after surgical resection. They were all submitted to the same therapeutic program after resection. There was no evidence of predisposing conditions such as hepatolithiasis and primary sclerosing cholangitis, a serious structural disease in these cases. The Ethics Committee of the Tianjin Medical University Cancer Institute and Hospital approved the study and all patients gave written informed consent to participate.

\section{Immunohistochemistry}

Four-micrometer tissue sections were cut, placed on silane-pretreated slides, deparaffinized, and rehydrated through graded alcohols. Antigen retrieval was performed by microwave heating at high power $(750 \mathrm{~W})$ in $10 \mathrm{mM}$ sodium citrate buffer, $\mathrm{pH} 6$, for 4 cycles of 5 min each. Slides were then allowed to cool for 30 min prior to incubation with the snail monoclonal antibody (Santa Cruz Biotechnology, USA) diluted 1:200, the E-cadherin monoclonal antibody (Santa Cruz Biotechnology) diluted 1:200, or the anti-PAN monoclonal antibody (clone MIB1; Biogenex, USA) diluted 1:50 for $1 \mathrm{~h}$ at room temperature. Staining was performed with the Envision monoclonal system (Dako, USA) and the reaction was developed with diaminobenzidine. Slides were counterstained with Mayer's hematoxylin and mounted. Non-immune mouse serum was used as negative control. Lymphocytes were used as the internal positive control for snail. Immunohistochemical staining of snail was defined as detectable immunoreactions in perinuclear region and/ or cytoplasm (20). Snail expression was considered to be negative when no more than $1 \%$ of the cells were positive, low when 1 to $49 \%$ of the cells were positive, and high when more than $50 \%$ of the cells were positive. Expression of E-cadherin was compared between malignant cells and normal epithelial cells located distant from the tumor. Tumor cells that stained as strongly as normal epithelial cells were considered to have preserved expression, whereas those that exhibited weaker staining patterns than normal epithelial cells or did not stain at all were considered to have reduced expression (21).

\section{RNA extraction and RT-PCR analysis}

Total RNA was isolated with Trizol reagent (Invitrogen, USA). RNA ( $2 \mu \mathrm{g}$ ) was reverse transcribed, and $2 \mu \mathrm{L}$ cDNA was amplified as follows: snail $=$ denaturation at $94^{\circ} \mathrm{C}$ for $60 \mathrm{~s}$; annealing at $58^{\circ} \mathrm{C}$ for $30 \mathrm{~s}$, extension at $72^{\circ} \mathrm{C}$ for 60 $\mathrm{s}$, followed by 25 cycles, forward primer $5^{\prime}$-gaattcatgcc gcgctccttcctcgtcaag-3', and reverse primer 5'-gcgatcgctc agtgtgccacacagcagcca-3'. E-cadherin = denaturation at $94^{\circ} \mathrm{C}$ for $60 \mathrm{~s}$, annealing at $60^{\circ} \mathrm{C}$ for $30 \mathrm{~s}$, biognostic extension at $72^{\circ} \mathrm{C}$ for $60 \mathrm{~s}$, followed by 28 cycles, forward primer 5'-ttcagttccgaggtctacac-3', and reverse primer $5^{\prime}$-gtctctgtggtgatgccggt-3'. $\beta$-actin $=25$ cycles at $94^{\circ} \mathrm{C}$ for $1 \mathrm{~min}, 53^{\circ} \mathrm{C}$ for $30 \mathrm{~s}$, and $72^{\circ} \mathrm{C}$ for $1 \mathrm{~min}$, forward primer $5^{\prime}$-atctggcacaccttctacaatgagctgcg-3', and reverse primer 5'-cgtcatactcctgcttgctgatccacatctgc-3'. All oligonucleotide primers were designed and synthesized by Takara (China), and the expression of $\beta$-actin mRNA was used as an internal control. The $\beta$-actin band on the gel acted as a standard band, and the density of snail and E-cadherin was evaluated by expressing their density relative to the $\beta$-actin standard band by densitometry. Thus, densitometry was performed on all gels and each signal was normalized to the correspond- 
ing $\beta$-actin signal using the Quantity One Image Analysis software (Biorad Laboratory, USA).

\section{Statistical analysis}

Survival times were calculated from the date of initial diagnosis. Associations between the relative risk of fatality and the various categories of single prognostic variables were evaluated according to Cox's proportional hazard regression model for censored data after dummy code transformation of the predictor. Survival curves were computed using the Kaplan-Meier product-limit method and compared using the log-rank test. Data are reported as means \pm SD for three replicate assays. Differences between groups were assessed by ANOVA or the $t$-test. A P value of $<0.05$ was considered to indicate statistical significance.

\section{Results}

\section{Snail and E-cadherin protein is expressed in hilar cholangiocarcinoma samples}

Immunostaining for the snail protein was always cytoplasmic, homogeneously distributed and with similar levels of intensity. In HC tissues, snail protein was localized in both neoplastic cells and fibroblastic cells of tumor desmoplastic reaction. The $47 \mathrm{HC}$ samples showed a heterogeneous pattern of positivity for snail expression in terms of the percentage of cells displaying clear-cut cytoplasmic staining. Twelve of 47 (26\%) HC samples showed negative snail expression (Figure 1A), 17 of 47 (36\%) samples showed low snail expression levels (Figure 1B), and 18 of $47(38 \%)$ samples showed high expression levels (Figure 1C). Among the samples with high snail expression levels, 10 samples were grade 2 and 8 samples were grade 3 . Among the samples with low expression levels, 12 were grade 2 and 5 were grade 3 (Table 1). Snail expression levels did not significantly correlate with gender, age, tumor grade, histological grade, tumor location, nodal metastasis and invasion, and vascular or perineural invasion (Table 1). E-cadherin expression level in $\mathrm{HC}$ samples was characterized by patterns with membrane staining (Figure 1D-F). Immunohistochemical staining revealed that $40.4 \%$ (19/47) of the HC samples showed reduced E-cadherin expression levels (Figure 1D) and 59.6\% (28/47) showed preserved E-cadherin expression levels (Figure 1E,F). No statistically significant correlations were found between snail and $E$-cadherin expression levels $(P=0.056$; Table 2). RT-PCR analysis of snail mRNA and E-cadherin mRNA showed the same results as immunohistochemical staining (Figure 2).

\section{Snail expression and its correlation with the MIB1 proliferation index}

The MIB1 labeling index was assessed in the $\mathrm{HC}$ of 45 patients, with 37 (82.2\%) displaying a low MIB1 index,
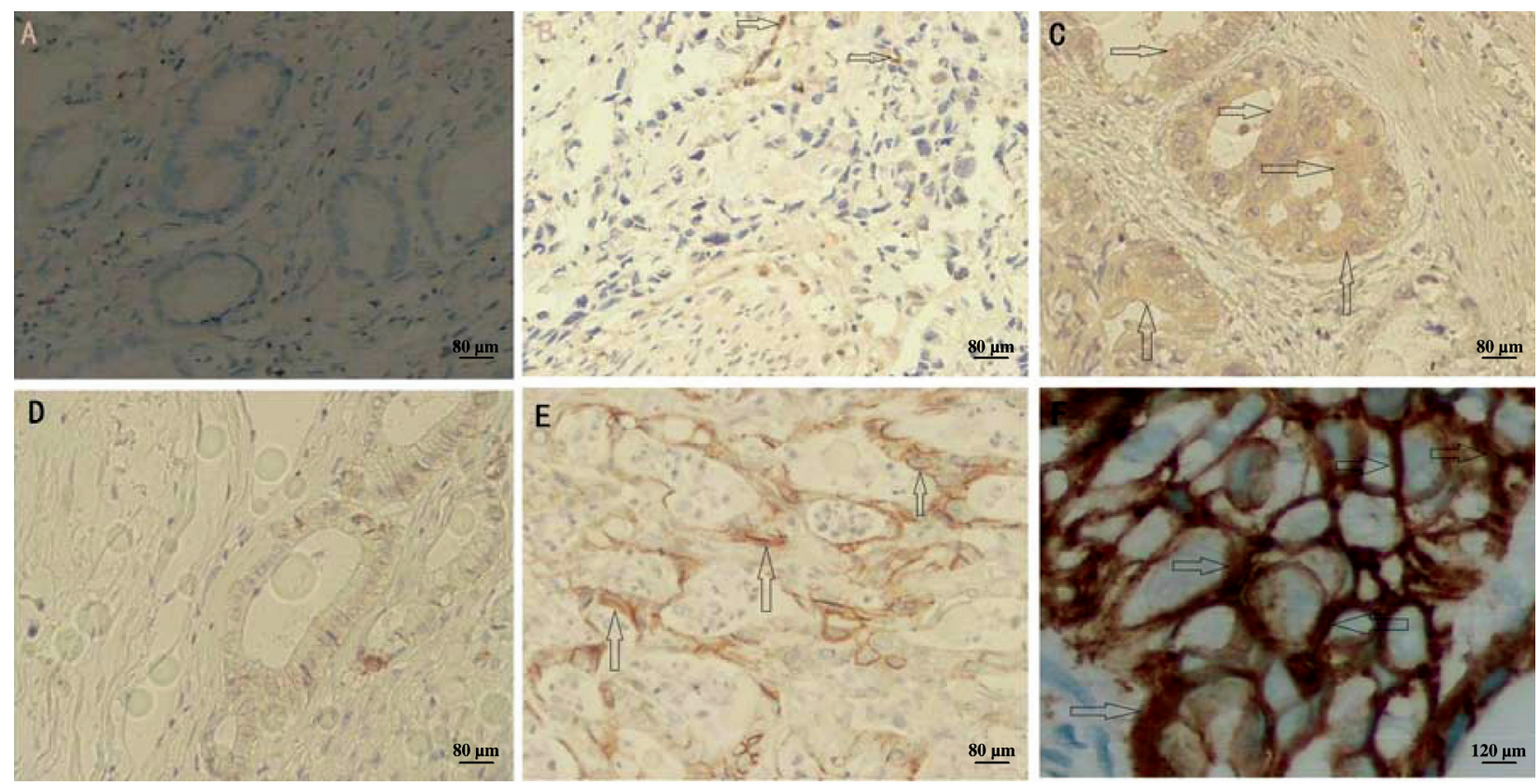

Figure 1. Immunohistochemical staining for snail and E-cadherin protein expression in hilar cholangiocarcinoma (HC). $A, \mathrm{Negative}$ snail expression in $\mathrm{HC}$ cells. $B$, Low expression of snail in $\mathrm{HC}$ cells. $C$, High expression of snail in $\mathrm{HC}$ cells. $D$, Reduced $\mathrm{E}$-cadherin expression in $\mathrm{HC}$ cells. $E$, Preserved $\mathrm{E}$-cadherin expression in $\mathrm{HC}$ cells. $F$, Preserved $\mathrm{E}$-cadherin expression in $\mathrm{HC}$ cells. The arrows indicate positive staining. 
whereas the remaining $8(17.8 \%)$ showed a high MIB1 index ( $\geq 10 \%$ of the neoplastic cells; Table 1$) \cdot x^{2}$ analysis showed no association between snail expression and MIB1 index. Likewise, proportional hazard regression analysis showed no association between MIB1 index and overall survival (Table 3).

\section{Snail and prediction of survival}

Survival data were available for 47 patients. The observation period ranged from 1 to 60 months, with a median survival of 20 months (confidence limits: 12 and 42 months) and a median time to censoring of 14 months (confidence limits: 10 and 20 months). At the most recent follow-up, 29 patients were alive and 18 had died. Kaplan-Meier survival curves did not show any significant relationship between tumor grade, tumor location, vascular or perineural invasion, and survival $(P>0.35$ for all by the log-rank test). Only 2 of $17(12 \%)$ patients in the low-expresser group died of the disease, compared to 17 of $18(94 \%)$ in the high expresser group (Table 3). The KaplanMeier survival curves comparing high, low, and no expression of snail showed a highly significant separation $(P<0.0001$; Figure 3). As can be seen in Table 3, when the variables were compared separately using univariate Cox proportional hazard regression, only snail was found to influence survival $(P=0.0003)$, with high snail expression carrying a 17 -fold higher risk of mortality than negative snail expression. Because only snail (of all variables examined) correlated with outcome, regression analysis was not explored further.

\section{Discussion}

This study on a relatively large series of 47 patients with resected $\mathrm{HC}$ has demonstrated for the first time the independent cinoma specimens. prognostic value of immunohistochemically determined snail overexpression. The results of the study were obtained from a highly homogenous series of $\mathrm{HC}$ from a singlecenter hospital.

Up to now, surgical resection has offered the only potential chance of cure in patients with $\mathrm{HC}(1,2)$. Usually, extensive resection is required to achieve adequate safety margins (22). In most patients, $\mathrm{HC}$ is present at an advanced stage and/or associated comorbidities preclude surgery,

Table 1. Snail expression and clinicopathological variables in 47 hilar cholangiocar-

\begin{tabular}{|c|c|c|c|c|c|}
\hline \multirow[t]{2}{*}{ Variable } & \multirow[t]{2}{*}{$\mathrm{N}$} & \multicolumn{3}{|c|}{ Snail expression } & \multirow[t]{2}{*}{$P\left(\right.$ Pearson $x^{2}$ test $)$} \\
\hline & & Negative & Low & High & \\
\hline Tumor grade & & & & & $X^{2}=0.91 ; P=0.633$ \\
\hline Grade 2 & 29 & 7 & 12 & 10 & \\
\hline Grade 3 & 18 & 5 & 5 & 8 & \\
\hline Histologic grade & & & & & $X^{2}=1.23 ; P=0.204$ \\
\hline Well differentiated & 27 & 7 & 12 & 8 & \\
\hline Moderately differentiated & 14 & 4 & 3 & 7 & \\
\hline Poorly differentiated & 6 & 1 & 2 & 3 & \\
\hline Vascular invasion & & & & & $X^{2}=0.08 ; P=0.962$ \\
\hline Absent & 32 & 8 & 12 & 12 & \\
\hline Present & 15 & 4 & 5 & 6 & \\
\hline Perineural invasion & & & & & $X^{2}=0.02 ; P=0.99$ \\
\hline Absent & 31 & 8 & 11 & 12 & \\
\hline Present & 16 & 4 & 6 & 6 & \\
\hline Nodal metastasis & & & & & $x^{2}=1.156 ; P=0.672$ \\
\hline Absent & 33 & 8 & 12 & 13 & \\
\hline Present & 14 & 4 & 5 & 5 & \\
\hline Lymphatic invasion & & & & & $x^{2}=1.283 ; P=0.782$ \\
\hline Absent & 24 & 7 & 7 & 10 & \\
\hline Present & 23 & 5 & 10 & 8 & \\
\hline Proliferation (MIB1a) & & & & & $X^{2}=0.48 ; P=0.289$ \\
\hline Low & 37 & 8 & 15 & 14 & \\
\hline High & 8 & 4 & 2 & 2 & \\
\hline
\end{tabular}

aOnly 45 cases were stained for MIB1 hilar cholangiocarcinoma.

Table 2. Comparison of snail and E-cadherin expression.

\begin{tabular}{lccc}
\hline Snail expression $(\mathrm{N}=47)$ & $\begin{array}{c}\text { E-cadherin expression } \\
\text { preserved }(\mathrm{N}=28)\end{array}$ & $\begin{array}{c}\text { E-cadherin expression } \\
\text { reduced }(\mathrm{N}=19)\end{array}$ & $\mathrm{X}^{2}$ test \\
\hline Negative expression $(\mathrm{N}=12)$ & 7 & 5 \\
Low expression $(\mathrm{N}=17)$ & 11 & 6 & \\
High expression $(\mathrm{N}=18)$ & 10 & 8 & $\mathrm{X}^{2}=3.25 ; \mathrm{P}=0.056$ \\
\hline
\end{tabular}

Differences between groups were assessed by the $x^{2}$ test. 


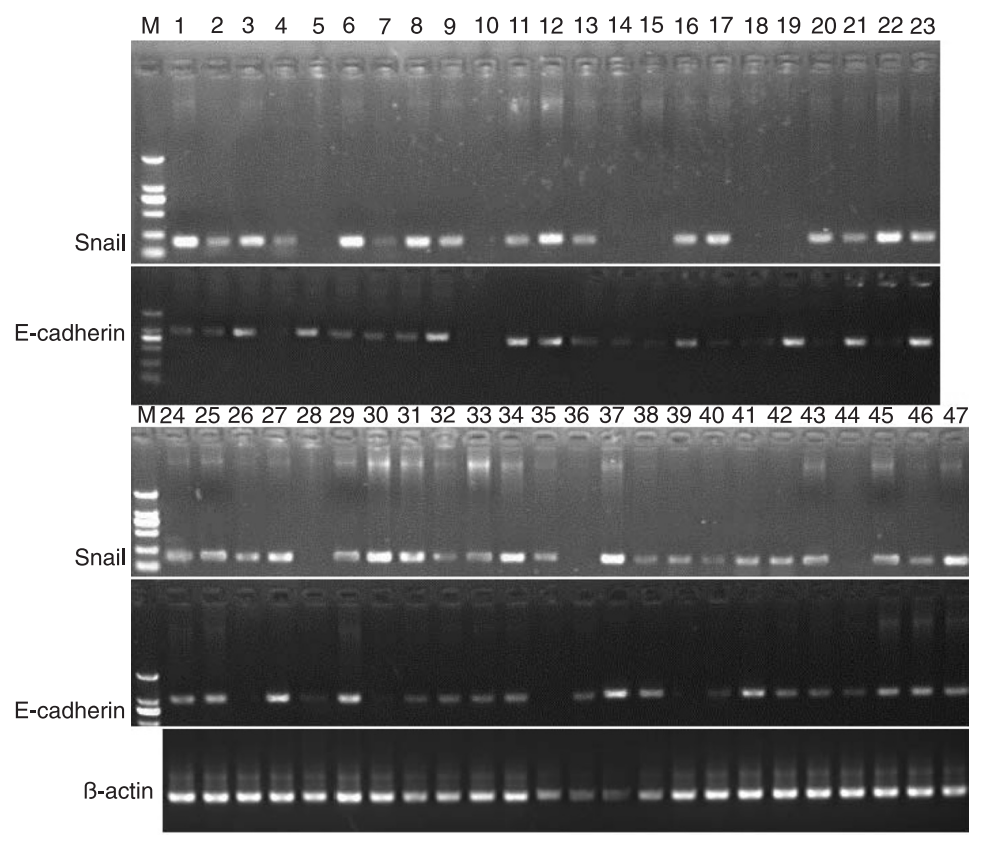

Figure 2. RT-PCR analysis showing comparative expression of snail and E-cadherin mRNA in 47 patients with hilar cholangiocarcinomas. $\beta$-actin mRNA expression was used as an internal control. $\mathrm{M}=$ molecular marker.

Table 3. Proportional hazard regression analysis of single predictors of survival.

\begin{tabular}{|c|c|c|c|c|}
\hline Variable & $\mathrm{N}$ & $\beta$ coefficient (SE) & Test & OR survival $(95 \% \mathrm{Cl})$ \\
\hline Age (years) & 47 & $0.024(0.024)$ & $X^{2}=1.03 ; P=0.309$ & \\
\hline \multicolumn{5}{|l|}{ Gender } \\
\hline Male & 22 & & & 1 \\
\hline Female & 25 & $-0.002(0.475)$ & $X^{2}=0.00 ; P=0.99$ & $1.0(0.39-2.53)$ \\
\hline \multicolumn{5}{|l|}{ Tumor grade } \\
\hline Grade 2 & 29 & & & 1 \\
\hline Grade 3 & 18 & $0.488(0.758)$ & $X^{2}=0.57 ; P=0.449$ & $1.45(0.56-3.77)$ \\
\hline \multicolumn{5}{|c|}{ Vascular invasion } \\
\hline Absent & 32 & & & 1 \\
\hline Present & 15 & $0.384(0.475)$ & $x^{2}=0.65 ; P=0.419$ & $1.47(0.58-3.72)$ \\
\hline \multicolumn{5}{|c|}{ Perineural invasion } \\
\hline Absent & 31 & & & 1 \\
\hline Present & 16 & $0.422(0.476)$ & $X^{2}=0.79 ; P=0.375$ & $1.52(0.6-3.87)$ \\
\hline \multicolumn{5}{|c|}{ Nodal metastasis } \\
\hline Absent & 33 & & & 1 \\
\hline Present & 14 & $0.364(0.463)$ & $X^{2}=0.74 ; P=0.456$ & $1.1(0.64-3.75)$ \\
\hline \multicolumn{5}{|c|}{ Lymphatic invasion } \\
\hline Absent & 24 & & & 1 \\
\hline Present & 23 & $0.406(0.474)$ & $X^{2}=0.89 ; P=0.405$ & $1.38(0.67-3.82)$ \\
\hline \multicolumn{5}{|l|}{ Proliferation } \\
\hline Low & 41 & & & 1 \\
\hline High & 6 & $0.051(0.643)$ & $x^{2}=0.06 ; P=0.937$ & $1.05(0.3-3.71)$ \\
\hline \multicolumn{5}{|l|}{ Snail } \\
\hline Negative & 12 & & & 1 \\
\hline Low & 17 & $1.44(0.844)$ & $X^{2}=2.91 ; P=0.087$ & $4.22(0.81-22.1)$ \\
\hline High & 18 & $2.84(0.79)$ & $X^{2}=12.89 ; P=0.0003$ & $17.07(3.63-80.35)$ \\
\hline
\end{tabular}

Wald test for regression coefficient. OR = odds ratio; $\mathrm{Cl}=$ confidence interval. OR is given only for categorical variables. 
and this patient group needs adequate palliation such as chemotherapy or photodynamic therapy (23-25).

Assessment of the individual prognosis of patients may be helpful to optimize decision making for surgical treatment and to avoid unnecessary surgical treatment. According to the results of the present study, the demonstration of snail expression level might be a candidate as an additional guide for the clinical management of patients with $\mathrm{HC}$. The immunohistochemically determined status of snail expression level qualifies as an independent prognostic parameter and thus offers additional information about the course of the disease over and above that offered by the well-established clinicopathologic prognostic parameters.

Snail is involved in many pathophysiological processes, including cell proliferation, metastasis, apoptosis, drug resistance, and several aspects of the carcinogenic process $(13,15,16,22)$. Snail expression has not yet been evaluated in any type of bile duct cancer, whereas hepatic tissue and $\mathrm{HC}$ have been the topic of study for the analysis of snail expression and regulation. Snail is expressed at high levels in human $\mathrm{HC}$ (18), a fact that fits well with our observation of a constant positive snail immunostaining in $\mathrm{HC}$.

Our data demonstrate that, as in other epithelial tumor types, HC patients who express high levels of snail fare worse than those with tumors that lack snail expression, independent of tumor grade or subtype. No association was found between snail expression level and tumor grade. These findings underscore the concept that snail expression level is a specific biological trait that characterizes individual tumors independently of their morphological appearance.

It has been reported that snail, a transcription factor and E-cadherin repressor, is a novel prognostic factor in many carcinomas (26-29). However, expression of snail in $\mathrm{HC}$ showed no significant relation to the expression of E-cadherin (Table 2).

Regarding proliferation, a high MIB1 index has been associated with worse outcome in cholangiocarcinoma (30-33). Nevertheless, in our study, the MIB1 index did not correlate with either snail expression level or survival. In contrast to other studies on bile duct cancers, only a minority of our $\mathrm{HC}$ samples (13\%) showed a high MIB1 index (30). This finding does not need to be attributed to technical artifacts because lymphocyte aggregates within the tumors provided reliable internal controls. The generally low growth rate of $\mathrm{HC}$ might be related to the fact that they were already bulky and in an advanced stage at the time of surgery.

In our series of $47 \mathrm{HC}$, proportional hazard regression analysis (Table 3 ) showed that snail expression was the only significant predictor of survival $(P=0.0003)$. In keeping

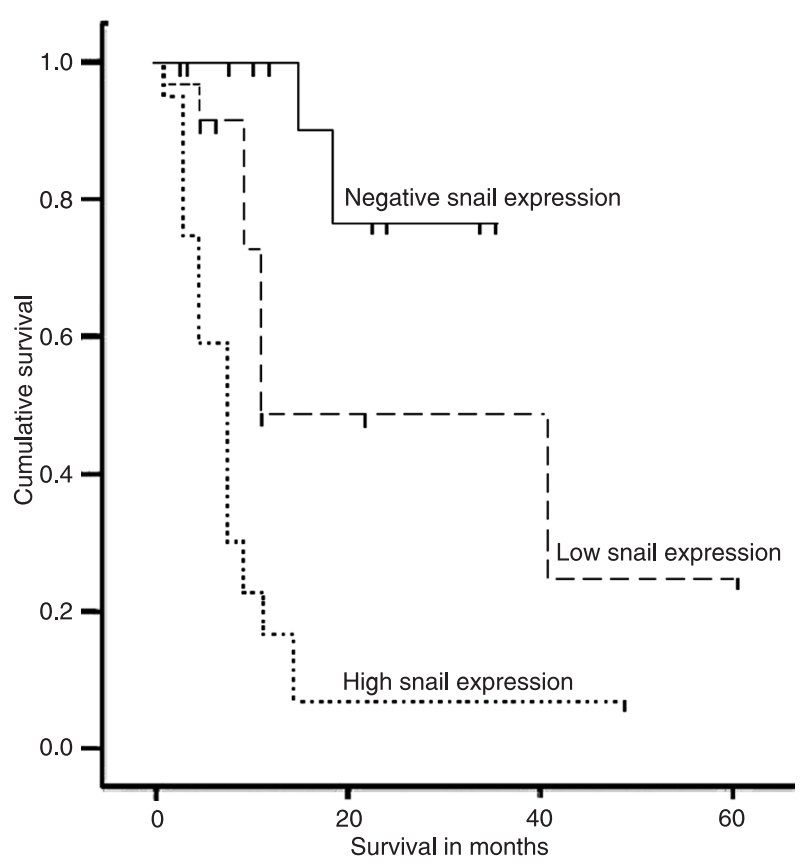

Figure 3. Kaplan-Meier estimated survival rates according to snail expression. Kaplan-Meier survival curves for negative and low snail expression versus high snail expression in 47 patients with hilar cholangiocarcinomas showed a highly significant separation (log-rank test, $X^{2}=23.86$; d.f. $=2 ; \mathrm{P}<0.0001$ ).

with the concept that pathological parameters do not have prognostic value in $\mathrm{HC}$, vascular or perineural invasion and tumor grade all failed to correlate with outcome.

In summary, as is the case for bile duct tumors, immunohistochemical detection of snail expression should provide the first biological predictor of survival for HC patients. A high snail expression level is also a better prognostic indicator than MIB1 index, because the former predicts poor survival regardless of tumor grade and stage. The highest 5-year survival rates for $\mathrm{HC}$ patients are achieved when complete tumor resection with negative margins can be obtained $(1,2)$. Thus, assessment of snail expression level could help predict the outcome of patients with $\mathrm{HC}$ and could also be useful for planning adjuvant therapies during follow-up.

We conclude that snail is overexpressed in $\mathrm{HC}$ samples. Snail expression levels can predict poor survival, regardless of pathological features and tumor proliferation. Immunohistochemical detection of snail expression levels on routine sections may provide the first biological prognostic marker. 


\section{References}

1. Park J, Kim MH, Kim KP, Park dH, Moon SH, Song TJ, et al. Natural history and prognostic factors of advanced cholangiocarcinoma without surgery, chemotherapy, or radiotherapy: a large-scale observational study. Gut Liver 2009; 3: 298-305.

2. Igami T, Nishio H, Ebata T, Yokoyama $Y$, Sugawara G, Nimura $Y$, et al. Surgical treatment of hilar cholangiocarcinoma in the "new era": the Nagoya University experience. $J$ Hepatobiliary Pancreat Sci 2010; 17: 449-454.

3. de Martel C, Plummer M, Franceschi S. Cholangiocarcinoma: descriptive epidemiology and risk factors. Gastroenterol Clin Biol 2010; 34: 173-180.

4. Thiery JP, Sleeman JP. Complex networks orchestrate epithelial-mesenchymal transitions. Nat Rev Mol Cell Biol 2006; 7: 131-142.

5. Cardiff RD. Epithelial to mesenchymal transition tumors: fallacious or snail's pace? Clin Cancer Res 2005; 11: 85348537.

6. Hemavathy K, Ashraf SI, Ip YT. Snail/slug family of repressors: slowly going into the fast lane of development and cancer. Gene 2000; 257: 1-12.

7. Gavert N, Ben-Ze'ev A. Epithelial-mesenchymal transition and the invasive potential of tumors. Trends Mol Med 2008; 14: 199-209.

8. Thisse C, Thisse B, Schilling TF, Postlethwait JH. Structure of the zebrafish snail1 gene and its expression in wild-type, spadetail and no tail mutant embryos. Development 1993; 119: 1203-1215

9. De Craene B, Van Roy F, Berx G. Unraveling signalling cascades for the Snail family of transcription factors. Cell Signal 2005; 17: 535-547.

10. Barrallo-Gimeno A, Nieto MA. The Snail genes as inducers of cell movement and survival: implications in development and cancer. Development 2005; 132: 3151-3161.

11. Carver EA, Jiang R, Lan Y, Oram KF, Gridley T. The mouse snail gene encodes a key regulator of the epithelial-mesenchymal transition. Mol Cell Biol 2001; 21: 8184-8188.

12. Parker BS, Argani $P$, Cook BP, Liangfeng $H$, Chartrand SD, Zhang $\mathrm{M}$, et al. Alterations in vascular gene expression in invasive breast carcinoma. Cancer Res 2004; 64: 78577866.

13. Martin TA, Goyal A, Watkins G, Jiang WG. Expression of the transcription factors snail, slug, and twist and their clinical significance in human breast cancer. Ann Surg Oncol 2005; 12: $488-496$

14. Peinado H, Olmeda D, Cano A. Snail, Zeb and bHLH factors in tumour progression: an alliance against the epithelial phenotype? Nat Rev Cancer 2007; 7: 415-428.

15. Imai T, Horiuchi A, Wang C, Oka K, Ohira S, Nikaido T, et al. Hypoxia attenuates the expression of E-cadherin via upregulation of SNAIL in ovarian carcinoma cells. Am J Pathol 2003; 163: 1437-1447.

16. Poser I, Dominguez D, de Herreros AG, Varnai A, Buettner R, Bosserhoff AK. Loss of E-cadherin expression in melanoma cells involves up-regulation of the transcriptional repressor Snail. J Biol Chem 2001; 276: 24661-24666.

17. Takkunen M, Grenman R, Hukkanen M, Korhonen M, Garcia de Herreros A, Virtanen I. Snail-dependent and -independent epithelial-mesenchymal transition in oral squamous carcinoma cells. J Histochem Cytochem 2006; 54: 12631275.

18. Sugimachi K, Tanaka S, Kameyama T, Taguchi K, Aishima $\mathrm{S}$, Shimada M, et al. Transcriptional repressor snail and progression of human hepatocellular carcinoma. Clin Cancer Res 2003; 9: 2657-2664.

19. Zhang KJ, Zhang BY, Zhang KP, Tang LM, Liu SS, Zhu DM, et al. Clinicopathologic significance of slug expression in human intrahepatic cholangiocarcinoma. World J Gastroenterol 2010; 16: 2554-2557.

20. Hotz B, Arndt M, Dullat S, Bhargava S, Buhr HJ, Hotz HG. Epithelial to mesenchymal transition: expression of the regulators snail, slug, and twist in pancreatic cancer. Clin Cancer Res 2007; 13: 4769-4776.

21. Shiozaki H, Tahara H, Oka H, Miyata M, Kobayashi K, Tamura S, et al. Expression of immunoreactive E-cadherin adhesion molecules in human cancers. Am J Pathol 1991; 139: $17-23$

22. Zhuo W, Wang Y, Zhuo X, Zhang Y, Ao X, Chen Z. Knockdown of Snail, a novel zinc finger transcription factor, via RNA interference increases A549 cell sensitivity to cisplatin via JNK/mitochondrial pathway. Lung Cancer 2008; 62: 8-14.

23. Lang $H$, Kaiser GM, Zopf $T$, Sotiropoulos GC, Frilling A, Malago $\mathrm{M}$, et al. [Surgical therapy of hilar cholangiocarcinoma]. Chirurg 2006; 77: 325-334.

24. Quyn AJ, Ziyaie D, Polignano FM, Tait IS. Photodynamic therapy is associated with an improvement in survival in patients with irresectable hilar cholangiocarcinoma. HPB 2009; 11: 570-577.

25. Fuks D, Bartoli E, Delcenserie R, Yzet T, Celice P, Sabbagh $\mathrm{C}$, et al. Biliary drainage, photodynamic therapy and chemotherapy for unresectable cholangiocarcinoma with jaundice. J Gastroenterol Hepatol 2009; 24: 1745-1752.

26. Mikami S, Katsube K, Oya M, Ishida M, Kosaka T, Mizuno R, et al. Expression of Snail and Slug in renal cell carcinoma: E-cadherin repressor Snail is associated with cancer invasion and prognosis. Lab Invest 2011; 91: 1443-1458.

27. Nassar A, Sookhan N, Santisteban M, Bryant SC, Boughey JC, Giorgadze T, et al. Diagnostic utility of snail in metaplastic breast carcinoma. Diagn Pathol 2010; 5: 76.

28. Kosaka T, Kikuchi E, Mikami S, Miyajima A, Shirotake S, Ishida $\mathrm{M}$, et al. Expression of snail in upper urinary tract urothelial carcinoma: prognostic significance and implications for tumor invasion. Clin Cancer Res 2010; 16: 58145823

29. Emadi Baygi M, Soheili ZS, Schmitz I, Sameie S, Schulz WA. Snail regulates cell survival and inhibits cellular senescence in human metastatic prostate cancer cell lines. Cell Biol Toxicol 2010; 26: 553-567.

30. Rijken AM, Umezawa A, van Gulik TM, Bosma A, Polak MM, Offerhaus GJ, et al. Prognostic value of cell proliferation (Ki-67 antigen) and nuclear DNA content in clinically resectable, distal bile duct carcinoma. Ann Surg Oncol 1998; 5: 699-705.

31. Fiorentino M, Altimari A, D'Errico A, Gabusi E, Chieco P, Masetti $\mathrm{M}$, et al. Low p27 expression is an independent predictor of survival for patients with either hilar or peripheral intrahepatic cholangiocarcinoma. Clin Cancer Res 2001; 7: 
3994-3999.

32. Aloysius MM, Hewavisenthi SJ, Bates TE, Rowlands BJ, Lobo DN, Zaitoun AM. Predictive value of tumor proliferative indices in periampullary cancers: $\mathrm{Ki}-67$, mitotic activity index (MI) and volume corrected mitotic index (M/V) using tissue microarrays. World J Surg 2010; 34: 2115-2121.

33. Shrestha ML, Miyake H, Kikutsuji T, Tashiro S. Prognostic significance of $\mathrm{Ki}-67$ and p53 antigen expression in carcinomas of bile duct and gallbladder. J Med Invest 1998; 45: 95-102. 